Quim. Nova, Vol. 29, No. 2, 200-202, 2006

\title{
AVALIAÇÃO DO ÓLEO ESSENCIAL DE Aloysia sellowii (BRIQUET) MOLDENKE (VERBENACEAE) DO SUL DO BRASIL
}

\author{
Marcelo Rossato \\ Departamento de Ciências Exatas e da Natureza, Instituto de Biotecnologia, Universidade de Caxias do Sul, Rua Francisco \\ Getúlio Vargas, 1130, 95020-972 Caxias do Sul - RS \\ Ana Cristina Atti dos Santos* e Luciana Atti Serafini \\ Departamento de Física e Química, Centro de Ciências Exatas e Tecnologia, Instituto de Biotecnologia, Universidade de \\ Caxias do Sul, Rua Francisco Getúlio Vargas, 1130, 95020-972 Caxias do Sul - RS \\ Fabiana Agostini e Marcia Regina Pansera \\ Instituto de Biotecnologia, Universidade de Caxias do Sul, Rua Francisco Getúlio Vargas, 1130, 95020-972 Caxias do Sul - RS \\ Ronaldo Wasum \\ Herbário da Universidade de Caxias do Sul, Rua Francisco Getúlio Vargas, 1130, 95020-972 Caxias do Sul - RS \\ Rosa Lia Barbieri \\ Embrapa Clima Temperado, CP 403, 96001-970 Pelotas - RS \\ Recebido em 19/10/04; aceito em 19/8/05; publicado na web em 3/2/06

\begin{abstract}
EVALUATION OF THE ESSENTIAL OIL OF Aloysia sellowii (BRIQUET) MOLDENKE (VERBENACEAE) FROM SOUTH BRAZIL. This work was performed with the aim of evaluating the chemical variability among samples of Aloysia sellowii (Verbenaceae) collected in different geographical regions as well as the application of supercritical $\mathrm{CO}_{2}$ for obtaining essential oil. Thus, samples were collected in different localities and oils were isolated by hydrodistillation and supercritical $\mathrm{CO}_{2}$. Results showed existence of two chimiotypes in the species (cineole and sabinene). The supercritical $\mathrm{CO}_{2}$ extraction process was appropriate for
\end{abstract} \\ extraction of A. sellowii essential oil at $40{ }^{\circ} \mathrm{C}, 110 \mathrm{bar}, 2 \mathrm{~mL} / \mathrm{min}$ of flow and $10 \mathrm{~min}$ of extraction time.
}

Keywords: Aloysia sellowii; essential oil; chimiotypes.

\section{INTRODUÇÃO}

A família Verbenaceae compreende 100 gêneros distribuídos nas regiões tropical e subtropical de todo o mundo ${ }^{1}$. Das espécies desta família, apenas Lippia citriodora é explorada comercialmente na Europa para produção de óleo essencial, conhecido como óleo de verbena, amplamente utilizado em perfumaria ${ }^{2}$. Além desta espécie, Lippia alba também já foi avaliada quanto ao seu potencial aromático, apresentando resultados interessantes em termos do composto linalol, presente em elevadas concentrações no óleo essencial $(50,0-79,2 \%)^{3,4}$. O óleo essencial de Lippia alba também demonstrou potencial antioxidante semelhante ao efeito da vitamina $\mathrm{E}^{5}$.

Aloysia sellowii, também uma Verbenaceae, conhecida popularmente como garupá, cidrózinho ou erva-de-sepultura, é encontrada em grande parte do sul do Brasil, Uruguai, Paraguai e Argentina. No Rio Grande do Sul é utilizada popularmente como diurética, estomáquica e no tratamento de gripe e bronquite 6 . Durante a Guerra dos Farrapos (1835 - 1845), os soldados utilizavam esta planta em casos de mal-estar gástrico, ficando conhecida como erva-desoldado. Estudos preliminares com a espécie mostraram elevados teores de óleo essencial e, em alguns casos, diferenças na composição química majoritária ${ }^{7}$. Esta variabilidade química pode ocorrer naturalmente devido à influência da temperatura, à umidade relativa, à duração total de exposição ao sol e ao regime de ventos. Ainda, diferentes órgãos de uma mesma planta podem apresentar óleos essenciais com composição química, caracteres físico-químicos e odores bem distintos ${ }^{8}$.

\footnotetext{
*e-mail: acsantos@ucs.br
}

Além de todos estes fatores, deve-se levar em consideração a variabilidade genética das plantas, que é expressa através dos chamados quimiotipos (QT) ${ }^{9}$. Segundo alguns autores, QT é um termo aplicado a plantas de mesmo gênero e espécie, com a mesma aparência externa, mas que diferem, às vezes consideravelmente, em sua composição química. Esses QT usualmente ocorrem naturalmente em plantas silvestres, e podem resultar parcialmente de polinização cruzada $^{8,10}$.

Devido ao potencial de exploração desta espécie em função do seu alto teor de óleo, pela presença de compostos químicos de interesse e pela carência de trabalhos na literatura relacionados a esta espécie, este trabalho foi realizado com objetivo de avaliar a variabilidade química entre amostras de Aloysia sellowii, bem como a possibilidade de aplicação da tecnologia de extração com $\mathrm{CO}_{2}$ supercrítico para obtenção do óleo essencial. Este último processo apresenta algumas vantagens quando comparado aos processos convencionais de extração. O dióxido de carbono supercrítico, assim como a maioria dos fluidos supercríticos, tem densidade próxima à de um líquido, baixa viscosidade e se difunde como um gás. Estas características lhe conferem excelentes qualidades de extração ${ }^{11}$.

\section{PARTE EXPERIMENTAL}

\section{Verificação de quimiotipos na espécie}

Para avaliação da variabilidade química de A. sellowii, foram coletadas amostras contendo ramos com folhas e flores nos municípios de Gramado Xavier (Outubro/2001-HUCS23060), Caçapava do Sul (Outubro/2001-HUCS19689, Fevereiro/2002- HUCS20450, 
Novembro/2002- HUCS21105), Caxias do Sul (Setembro/2002HUCS20609) e Camaquã (Novembro/2001- HUCS23061), RS. De cada coleta, uma amostra foi depositada no Herbário da Universidade de Caxias do Sul (HUCS) para registro. O material vegetal utilizado nos experimentos foi desidratado a $30{ }^{\circ} \mathrm{C}$ por 4 dias em sala de secagem com temperatura controlada e circulação de ar.

O óleo essencial foi obtido do material vegetal contendo ramos, folhas e flores por hidrodestilação em aparelho Clevenger, descrito por Mechkovski e Akerele ${ }^{11}$. Cerca de $100 \mathrm{~g}$ do material a ser extraído foi colocado em balão de fundo redondo de $5.000 \mathrm{~mL}$, juntamente com cerca de $2.500 \mathrm{~mL}$ de água. O princípio do método consistiu em evaporar a mistura do material vegetal e água. $\mathrm{O}$ vapor formado foi condensado, e o óleo, que é imiscível com a água, foi facilmente separado. Após extração, o teor do óleo, em termos de volume/peso, foi lido diretamente no próprio aparelho e convertido a peso/peso utilizando-se a densidade do óleo essencial $\left(0,886 \mathrm{~g} / \mathrm{cm}^{3}\right)$. Este produto foi secado com $\mathrm{Na}_{2} \mathrm{SO}_{4}$ anidro.

\section{Extração com $\mathrm{CO}_{2}$ supercrítico}

Os testes em extração supercrítica foram realizados com o material vegetal coletado no mês de setembro de 2003, em Caxias do Sul (HUCS20609). Para realização dos experimentos foi utilizado módulo de bancada HP 7680T da Hewlett Packard contendo célula de extração em aço inoxidável autosselante de $7 \mathrm{~mL}$ e coletor analítico ODS (Hypersil octadecylsilica) para retenção do extrato com volume de $540 \mu \mathrm{L}$. Para lavagem do coletor foi o utilizado hexano PA. As extrações foram realizadas a partir de 1,0 $\mathrm{g}$ de material vegetal seco e o solvente supercrítico utilizado foi $\mathrm{CO}_{2}$ líquido industrial fornecido pela empresa Air Products. As condições experimentais foram selecionadas em função de trabalhos anteriores publicados em extração supercrítica ${ }^{13-15}$ e as limitações do equipamento: $40^{\circ} \mathrm{C}$ para temperatura, 110 bar para pressão e $2 \mathrm{~mL} / \mathrm{min}$ para vazão do $\mathrm{CO}_{2}$. Testes foram realizados utilizandose diferentes tempos de extração (3 a $60 \mathrm{~min}$ ), sendo que o mais adequado foi determinado a partir da obtenção de maior teor de óleo essencial.

\section{Extração supercrítica $x$ hidrodestilação}

Para comparação entre processos, foram utilizados os parâmetros pré-estabelecidos no item anterior utilizando $\mathrm{CO}_{2}$ supercrítico, e em hidrodestilação com tempo de extração de $1 \mathrm{~h}$.

\section{Identificação dos compostos químicos do óleo essencial}

Foram realizadas análises cromatográficas em cromatógrafo HP 6890 equipado com processador de dados e coluna capilar HP-
Innowax (30 m x $320 \mu \mathrm{m}$ d.i., 0,50 $\mu \mathrm{m}$ de espessura de filme; HP, Palo Alto, USA). O programa de temperatura da coluna foi: $40{ }^{\circ} \mathrm{C}$ $(8$ min $)$ a $180{ }^{\circ} \mathrm{C}$ à $3{ }^{\circ} \mathrm{C} / \mathrm{min}, 180-230^{\circ} \mathrm{C}$ à $20^{\circ} \mathrm{C} / \mathrm{min}, 230^{\circ} \mathrm{C}(20$ min). A temperatura do injetor foi de $250{ }^{\circ} \mathrm{C}$, a temperatura do detector foi de $250^{\circ} \mathrm{C}$, o gás de arraste utilizado foi $\mathrm{H}_{2}$ na pressão de $34 \mathrm{kPa}$ e a razão de "split" foi de 1:50. O volume injetado de amostra foi $1 \mu \mathrm{L}$ diluído em hexano (1:10) para a amostra obtida pelo processo de hidrodestilação e $1 \mu \mathrm{L}$ para as amostras obtidas em extração supercrítica. As análises qualitativas foram realizadas em cromatógrafo gasoso acoplado a detector seletivo de massas GC6890/ MSD5973 HP, equipado com biblioteca de espectros Wiley 275. Uma coluna capilar HP-Innowax (30 m x $250 \mu \mathrm{m}, 0,25 \mu \mathrm{m}$ de espessura de filme; HP, Palo Alto, USA) foi utilizada. O programa de temperatura foi o mesmo usado nas análises em cromatógrafo gasoso. Neste caso, a temperatura da interface foi de $280^{\circ} \mathrm{C}$, a razão de "split" foi de 1:100, o gás de arraste utilizado foi He na pressão de $56 \mathrm{kPa}$, a razão de fluxo selecionada foi $1 \mathrm{~mL} / \mathrm{min}$, a energia de ionização foi de $70 \mathrm{eV}$, a faixa de massa foi de 40-350 e o volume injetado de amostra foi $0,6 \mu \mathrm{L}$.

A identificação dos componentes foi realizada por comparação dos espectros de massa dos compostos com os da biblioteca Wiley e por comparação com dados descritos na literatura ${ }^{16}$. A quantificação dos extratos foi realizada por cromatografia gasosa após estabelecimento dos parâmetros mais adequados, utilizando-se $100 \mu \mathrm{L}$ de 1-octanol como padrão interno na concentração de 30,923 g/L.

\section{RESULTADOS E DISCUSSÃO}

A análise química das amostras mostrou a provável existência de dois QT (Tabela 1). É possível que as amostras 23060, 20609 e 21105 pertençam a um QT denominado 1,8-cineol (Figura 1), já que este é o composto majoritário em ambas as amostras. Este composto é um éter usado em preparações farmacêuticas, tanto para uso externo quanto interno, usado também em loções, cosméticos e aromatizadores de ambiente $^{17}$. Além destas aplicações, o 1,8-cineol apresenta importantes atividades farmacológicas como expectorante, fungicida, em especial agindo sobre Candida albicans, e bactericida com ação sobre Staphylococcus aureus e $S$. alba ${ }^{10}$. Um outro possível QT, denomi-
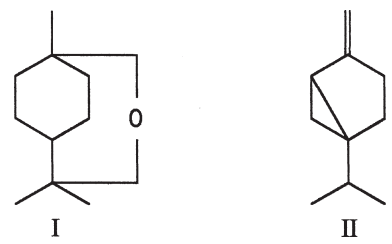

Figura 1. Fórmula molecular dos compostos majoritários presentes nas amostras de Aloysia sellowii, 1,8-cineol (I) e sabineno (II)

Tabela 1. Composição química majoritária de óleo essencial de diferentes amostras de Aloysia sellowii (Briquet) Moldenke

\begin{tabular}{|c|c|c|c|c|c|c|c|}
\hline \multirow[t]{2}{*}{ Composto } & \multirow{2}{*}{$\begin{array}{l}\text { Tempo de } \\
\text { retenção }\end{array}$} & \multicolumn{6}{|c|}{ Amostras } \\
\hline & & 23060 & 19689 & 23061 & 20450 & 20609 & 21105 \\
\hline$\alpha$-pineno & $4,34 \mathrm{~min}$ & $3,88 \%$ & $2,92 \%$ & $3,65 \%$ & $2,28 \%$ & $4,90 \%$ & $3,82 \%$ \\
\hline$\beta$-pineno & $7,57 \mathrm{~min}$ & $14,82 \%$ & $10,19 \%$ & $3,04 \%$ & $9,41 \%$ & $0,33 \%$ & $\mathrm{t}$ \\
\hline sabineno & $8,59 \mathrm{~min}$ & $2,75 \%$ & $39,67 \%$ & $62,5 \%$ & $28,64 \%$ & $11,39 \%$ & $9,09 \%$ \\
\hline limoneno & $12,68 \mathrm{~min}$ & $9,50 \%$ & $13,41 \%$ & $1,28 \%$ & $11,96 \%$ & $6,27 \%$ & $5,76 \%$ \\
\hline 1,8-cineol & $13,05 \mathrm{~min}$ & $16,11 \%$ & $2,63 \%$ & $3,30 \%$ & $0,57 \%$ & $40,11 \%$ & $34,06 \%$ \\
\hline germacreno & $34,47 \mathrm{~min}$ & $7,00 \%$ & $0,54 \%$ & $4,92 \%$ & $0,60 \%$ & $14,32 \%$ & $13,56 \%$ \\
\hline biciclogermacreno & $35,38 \mathrm{~min}$ & $4,49 \%$ & $2,55 \%$ & $3,94 \%$ & $7,63 \%$ & $3,55 \%$ & $2,67 \%$ \\
\hline Teor de óleo essencial (\%p/p) & & 0,39 & 0,59 & 0,93 & 0,55 & 0,48 & 1,06 \\
\hline
\end{tabular}

t: concentração menor que $0,01 \%$ 
nado sabineno (Figura 1), foi observado nas amostras 19689, 23061 e 20450. Sabineno é um monoterpeno bicíclico pouco usado comercialmente de maneira direta, mas que tem sido aplicado na preparação de vários óleos essenciais artificiais ${ }^{18}$.

É importante comentar que a amostra 20609 foi coletada em Caxias do Sul, mas foi introduzida a partir de mudas provenientes de Caçapava do Sul, há pelo menos dez anos. Esta planta é quimicamente semelhante à amostra 21105, coletada em Caçapava do Sul, porém apresentando algumas diferenças de compostos minoritários, que podem ocorrer por mudanças ambientais e geográficas, entre outras.

Provavelmente as diferenças observadas em A. sellowii são provenientes das condições ecológicas e de sua composição genética, considerando que a região de Caçapava do Sul é uma região de transição entre o planalto meridional, cuja altitude média é 800 m, e a depressão central do Estado do Rio Grande do Sul, o que justificaria a presença de populações de Aloysia com diferentes quimiotipos.

Muitos fatores afetam o teor de um óleo essencial, em termos de qualidade e quantidade. O local de crescimento da planta, a hora em que a planta é coletada, a luz, a altitude, a temperatura e as chuvas podem ter efeitos críticos na quantidade e qualidade dos óleos essenciais $^{10}$. Na Tabela 1 também podem ser observadas as variações de teor entre as amostras coletadas em diferentes locais e períodos do ano, onde os maiores valores ocorreram nas amostras 23061 e 21105 , ambas coletadas no mês de novembro.

A avaliação do processo de extração com $\mathrm{CO}_{2}$ supercrítico foi realizada a partir da variação do tempo de processo (Figura 2), onde se observa que, para um tempo de 10 min, todo o óleo essencial foi extraído $(0,40 \% \mathrm{p} / \mathrm{p})$. Material vegetal coletado no mesmo período em condições semelhantes e submetido ao processo de hidrodestilação pelo período de $1 \mathrm{~h}$ resultou em 1,85\% p/p de óleo essencial.

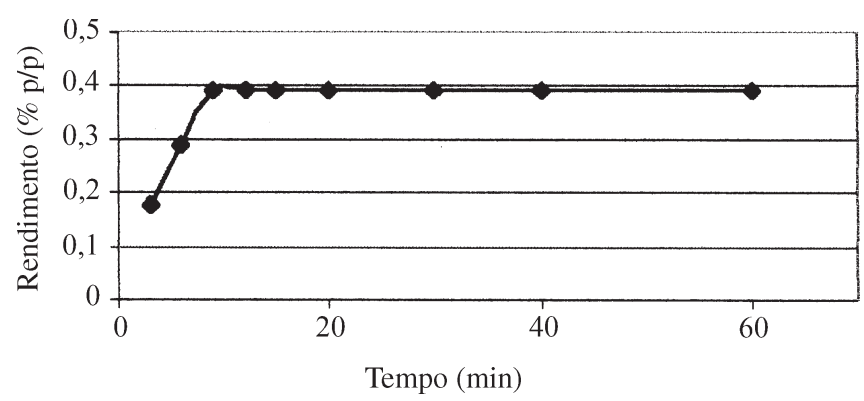

Figura 2. Curva de rendimento para o óleo essencial de Aloysia sellowii extraído à $40{ }^{\circ} \mathrm{C}, 110$ bar e vazão de $2 \mathrm{~mL} / \mathrm{min}$ em função do tempo de processo

Analisando os dois processos observa-se que em hidrodestilação são obtidos teores superiores (em $1 \mathrm{~h}$ ); por outro lado, convém lembrar que o processo de extração supercrítica apresenta diversas vantagens, entre elas a possibilidade de variação dos parâmetros de extração. Em termos de composição química do óleo essencial, observaram-se concentrações semelhantes do composto 1,8-cineol nas amostras obtidas pelos 2 processos $(15,2 \%$ para extração supercrítica e $12,52 \%$ para hidrodestilação).

\section{CONCLUSÕES}

A espécie Aloysia sellowii apresenta os compostos 1,8-cineol e sabineno em tecidos de ramos, folhas e flores.

As amostras 23060 procedente de Gramado Xavier, 20609 de Caxias do Sul e 21105 de Caçapava do Sul possuem como composto majoritário 1,8-cineol. As amostras 19689 de Caçapava do Sul, 23061 de Camaquã e 20450 de Caçapava do Sul possuem como composto majoritário sabineno. Esta variabilidade química entre as amostras indica a necessidade de estudos químicos prévios da amostra visando sua aplicação.

A extração supercrítica pode ser considerada um método rápido para extração do óleo essencial de A. sollowii, fornecendo resultados comparáveis aos obtidos por hidrodestilação, em termos de concentração do composto majoritário, 1,8-cineol.

\section{AGRADECIMENTOS}

Pesquisa realizada com apoio da Universidade de Caxias do Sul e Secretaria de Estado da Ciência e Tecnologia - RS.

\section{REFERÊNCIAS}

1. Joly, A. B.; Botânica: Introdução à Taxonomia Vegetal, $11^{\mathrm{a}}$ ed., Companhia Editora Nacional: São Paulo, 1993.

2. Craveiro, A. A.; Fernandes, A. G.; Andrade, C. H. S.; Matos, F. J. A.; Alencar, J. W. D.; Machado, M. I. L.; Óleos Essenciais de Plantas do Nordeste, UFC: Fortaleza, 1981.

3. Atti-Serafini, L.; Pansera, M. R.; Atti-Santos, A. C.; Rossato, M.; Pauletti, G. F.; Rota, L. D.; Paroul, N.; Moyna, P.; Revista Brasileira de Plantas Medicinais 2002, 4, 72.

4. Siani, A. C.; Tappin, M. R. R.; Ramos, M. F. S.; Mazzei, J. L.; Ramos, M. C. K. V.; Neto, F. R. A.; Frighetto, N.; J. Agric. Food. Chem. 2002, 50, 3518.

5. Stashenko, E. E.; Jaramillo, B. E.; Martinez, J. R.; J. Chromatogr., A 2004, $1025,93$.

6. Simionatto, E.; Porto, C.; Silva, U. F. D.; Hoenzel, S. C.; Ilhal, V.; Dessoy, E. C. M.; Morel, A. F.; Anais do 33 ${ }^{\text {rd }}$ International Symposium on Essential Oils, Lisboa, Portugal, 2002.

7. Agostini, F.; Atti-Santos, A. C.; Rossato, M.; Rota, L. D.; Wasum, R.; AttiSerafini, L.; Anais do II Simpósio Brasileiro de Óleos Essenciais, Campinas, Brasil, 2003.

8. Simões, C. M. O.; Spitzer, V.; Farmacognosia, Ed. da UFRGS: Porto Alegre, 2000.

9. Apel, M. A.; Tese de Doutorado, Universidade Federal do Rio Grande do Sul, Brasil, 2001.

10. Price, S.; Price, L.; Aromaterapy for Health Professionals, Churchill Livingstone: New York, 1999.

11. Maul, A. A.; Biotecnologia Ciência e Desenvolvimento 1999, 11, 42.

12. Mechkovski, A.; Akerele, C. O.; Quality control methods for medicinal plant materials, World Health Organization: Switzerland, 1992.

13. Atti-Santos, A. C.; Atti-Serafini, L.; Cassel, E.; Perfumer \& Flavorist 2000, 25, 26.

14. Paroul, N.; Rota, L.; Frizzo, C.; Atti-Santos, A. C.; Moyna, P.; Gower, A. E.; Atti-Serafini, L.; J. Essential Oils Res. 2002, 14, 282.

15. Atti-Santos, A. C.; Rossato, M.; Atti-Serafini, L.; Cassel, E.; Moyna, P.; Brazilian archives and Biology and Technology 2005, 48, 155.

16. Adams, R. P.; Identification of essential oils components by gas chromatography/Quadrupole mass spectroscopy, Allured: Carol Stream, 2001.

17. Guenther, E.; The Essential Oils, Krieger: Florida, 1975.

18. Arctander, S.; Perfume and Flavor Chemicals (Aroma Chemicals), Allured Publishing Corporation: USA, 2000. 